\title{
Maerua angolensis Extract Reduces Allodynia and Hyperalgesia in a Mouse Model of Vincristine-Induced Peripheral Neuropathy
}

\author{
Hosea Azi Iliya ${ }^{1,2}$, Wonder Kofi Mensah Abotsi ${ }^{2}$, Charles Benneh ${ }^{2}$, Eric Woode ${ }^{2 *}$ \\ ${ }^{1}$ Department of Pharmacology, University of Jos, Jos, Nigeria. ${ }^{2}$ Department of Pharmacology, Faculty of Pharmacy and Pharmaceutical Sciences, \\ College of Health Sciences, Kwame Nkrumah University of Science and Technology, Kumasi, Ghana.
}

\begin{tabular}{l} 
ARTICLE INFO \\
\hline Article history: \\
Received on: $30 / 12 / 2015$ \\
Revised on: $15 / 01 / 2016$ \\
Accepted on: 20/02/2016 \\
Available online: $28 / 05 / 2016$ \\
\hline Key words: \\
Maerua angolensis, \\
Neuropathic pain, Von Frey \\
filaments, allodynia, \\
hyperalgesia.
\end{tabular}

\begin{abstract}
Allodynia and hyperalgesia comprise the main and frequent symptoms suffered by patients with neuropathic pain, which responds poorly to therapy. An earlier study reported that stem bark extracts of Maerua angolensis exhibited dose-dependent anti-nociceptive effect against the neurogenic and inflammatory phases of the formalin test. The current study evaluated the effect of petroleum ether/ethyl acetate stem bark extract of Maerua angolensis on vincristine-induced neuropathy. Neuropathic pain was induced by intraperitoneal injection of vincristine $(0.1 \mathrm{mg} / \mathrm{kg} /$ day $)$ using a 5-day-on, 2-day-off schedule over 12 days. On day 15, baseline responses were measured in the Randall-Selitto mechanical hyperalgesia test and paw withdrawal tests (using Von Frey filaments and cold water at $4.5{ }^{\circ} \mathrm{C}$ ) and mice that developed allodynia/hyperalgesia were randomly assigned into 7 groups. Normal saline (i.p.), pregabalin $(10,30$, and $100 \mathrm{mg} / \mathrm{kg}$, p.o.) and extract $(3,10$, and 20 $\mathrm{mg} / \mathrm{kg}$, p.o.) were administered to the individual groups. Allodynia/hyperalgesia was measured hourly for 5 hours post treatment. The extract produced significant $(P<0.05)$ and dose-dependent inhibition of vincristineinduced mechanical hyperalgesia, tactile and cold allodynia responses. In all, the study shows that oral administration of Maerua angolensis stem bark extract inhibits vincristine-induced neuropathy in mice suggesting that it may exert analgesic effect in cancer patients with vincristine-induced neuropathic pain.
\end{abstract}

\section{INTRODUCTION}

Neuropathic pain is a common problem that presents a major challenge to health-care providers owing to its complex natural history, uncertain aetiology and poor response towards therapy (Quintans et al., 2014). It is a chronic pain condition that arises from a disease or injury to the central nervous system (CNS) or the peripheral nervous system (PNS) leading to its damage or abnormal function. Common symptoms of neuropathic pain include sensory abnormalities such as burning sensations, hyperalgesia, allodynia, hyperesthesia and dysesthesia (Schim, 2009). The current analgesics are unable to treat cancer chemotherapy-induced neuropathic pain which is severe enough for patients to discontinue their cancer chemotherapy treatment and worsens the quality of their life (Lynch et al., 2005; Wolf et al., 2008; Park et al., 2012).

\footnotetext{
* Corresponding Author

Eric Woode, Department of Pharmacology, Faculty of Pharmacy and Pharmaceutical Sciences, College of Health Sciences, Kwame Nkrumah University of Science and Technology, Kumasi, Ghana

Email: ewoode.pharm@knust.edu.gh
}

Thus, the search for new chemical entities that can act as promising molecules to treat chemotherapy-induced neuropathic pain has emerged. Medicinal plants are potential sources of commercial drugs and lead compounds in drug development (Zhang, 2004) forming important sources of new chemical substances with potential therapeutic effects (Ebadi, 2007). Maerua angolensis DC (Family: Capparidaceae) is a medicinal plant used traditionally to relieve pain (Mothana et al., 2009; Meda et al., 2013).

The petroleum ether/ethyl acetate stem bark extract of this plant has been demonstrated to possess anti-nociceptive effect in chemical, mechanical and thermal behavioural models of nociception in rodents (Iliya et al., 2014b). In another study (Iliya et al., 2014a), the authors speculated that the extracts could be effective against neuropathic pain since the second phase of the formalin test is predictive of activity in neuropathic pain models (Alessandri-Haber et al., 2004; Vissers et al., 2006). As a followup to confirm that assertion, the current study investigated the antinociceptive effect of the petroleum ether/ethyl acetate stem bark extract of Maerua angolensis in the vincristine-induced neuropathic pain model. 


\section{MATERIALS AND METHODS}

\section{Plant materials}

Fresh stem barks of Maerua angolensis were collected in August 2012 from the Samaru campus of Ahmadu Bello University, Zaria, Nigeria and were identified by Dr. Kofi Annan of the Department of Herbal Medicine, Faculty of Pharmacy and Pharmaceutical Sciences, Kwame Nkrumah University of Science and Technology (KNUST), Kumasi, Ghana. A voucher specimen (KNUST/FP/12/051) was kept at the herbarium of the Faculty.

\section{Extraction}

Four kilograms of the dried powdered stem bark was sequentially extracted with petroleum ether $(10 \mathrm{~L})$ and ethyl acetate $(10 \mathrm{~L})$ over a 4 -day period by cold maceration. The liquid extracts were filtered and each concentrated separately in a rotary evaporator under reduced temperature and pressure to give yellowish syrupy mass.

The extracts were further dried in an oven at $50{ }^{\circ} \mathrm{C}$ to obtain yields of $2.23 \%(\mathrm{w} / \mathrm{w})$ (petroleum ether) and $3.87 \%(\mathrm{w} / \mathrm{w})$ (ethyl acetate). Since thin-layer chromatography (TLC) analysis of the two extracts revealed similar composition of phytochemical constituents, the petroleum ether and the ethyl acetate extracts were combined. The combination is subsequently referred to as petroleum ether/ethyl acetate stem bark extract of Maerua angolensis or MAE in this study.

\section{Animals}

Male Swiss albino mice (20-25 g) were used after approval of protocol for the study by the local ethical committee for animal handling and experimental procedure. All animals were housed in groups of five in stainless steel cages $(34 \times 47 \times 18 \mathrm{~cm})$ with softwood shavings as bedding in the animal facility of the Department of Pharmacology, KNUST, with free access to food and water and were maintained under normal laboratory conditions of humidity, temperature $\left(25 \pm 1{ }^{\circ} \mathrm{C}\right)$ and a $12 \mathrm{~h} / 12 \mathrm{~h}$ day/night cycle. Each animal was used only once. The investigation conforms to the Guide for the Care and Use of Laboratory Animal published by the US National Institutes of Health (NIH No. 85-23, revised 1996). In all the experimental studies each group consisted of 5 animals.

\section{Drugs and chemicals}

Pregabalin (Pfizer Pharmaceuticals, Arzneimittelwerk Godecke, Freiburg, Germany) and vincristine sulphate (Celon Laboratory Ltd, Gajularamaram, India) were used.

\section{Phytochemical screening}

Preliminary phytochemical tests were performed on the extract using methods described by Trease and Evans (1989).

\section{Vincristine-induced neuropathic pain}

Vincristine sulphate was dissolved in normal saline and stored as a stock concentration of $1 \mathrm{mg} / 10 \mathrm{ml}$ at $4{ }^{\circ} \mathrm{C}$. Immediately following behavioural testing for mechanical, tactile and cold allodynia and/or hyperalgesia, the mice were administered vincristine $(0.1 \mathrm{mg} / \mathrm{kg} /$ day, i.p. $)$ or normal saline $(10 \mathrm{ml} / \mathrm{kg} / \mathrm{day}$, i.p) in two cycles of five consecutive days with two days off between the cycles (days 1-5 and days 8-12) to induce neuropathic pain On day 15, baseline responses were measured in the Von Frey filaments (4, 8 and $15 \mathrm{~g}$ ), Randall-Selitto mechanical hyperalgesia and cold allodynia (cold water at $4.5{ }^{\circ} \mathrm{C}$ ) tests. Mice that developed allodynia and/or hyperalgesia were randomly assigned into 7 groups and subsequently treated with MAE (3, 10, and 20 $\mathrm{mg} / \mathrm{kg}$, p.o.), pregabalin $(10,30$, and $100 \mathrm{mg} / \mathrm{kg}$, p.o.) or normal saline (10 $\mathrm{ml} / \mathrm{kg}$, i.p.).

Allodynia and/or hyperalgesia was measured at hourly intervals for 5 hours post-treatment using three sets of experiments namely Von Frey (tactile allodynia, intermediate and mechanical hyperalgesia) test, Randall-Selitto mechanical hyperalgesia test and cold allodynia (cold water at $4.5^{\circ} \mathrm{C}$ ) test to assess the effect of MAE on vincristine-induced neuropathic pain.

\section{Assessment of tactile allodynia, intermediate and mechanical hyperalgesia}

Tactile allodynia was evaluated by means of Von Frey filaments (IITC Life Science Inc. Model 2888, Woodland Hills, CA, USA) with bending forces of $4 \mathrm{~g}$. Intermediate and mechanical hyperalgesia were evaluated with Von Frey filaments of bending forces of 8 and $15 \mathrm{~g}$ respectively. Responses to $15 \mathrm{~g}$ are best explained as hyperalgesia (exaggerated pain response from a normally noxious stimulus) as normal mice withdraw from this stimulus $5-10 \%$ of the time; while the responses to $8 \mathrm{~g}$ are intermediate.

In ascending order of force, each filament was applied to the mid-plantar area (dodging the base of the tori) of each hind paw five times, with each application held for $5 \mathrm{~s}$. Withdrawal responses to the Von Frey filaments from both hind paws were counted and expressed as an overall percentage (Flatters et al., 2004; Siau et al., 2006).

\section{Assessment of mechanical hyperalgesia in the Randall-Selitto test}

Mechanical nociception was determined with the IITC Life Science Model 2888 (Woodland Hills, CA, USA). The mouse's hind paw was placed into the pressure applicator, and a constantly increasing pressure stimulus (maximum cut-off of 250 g) was applied to the dorsal surface of the paw until withdrawal or vocalization happened, at which weight the nociceptive threshold value was documented. For each mouse, two readings were documented for each hind paw, and the results reported as the mean value of readings from both hind paws (Woode et al., 2013).

\section{Assessment of cold allodynia}

Cold allodynia was evaluated by immersion of the animal's hind paw into a water bath containing cold water $\left(4.5^{\circ} \mathrm{C}\right)$ 
and latency to paw withdrawal was determined using a digital timer. Only one hind paw was assessed in each immersion at a time, with the maximum cut-off time of $20 \mathrm{~s}$. For each mouse two readings were documented for each hind paw, and the data reported as the mean of both hind paw values.

\section{Data analysis}

Data are expressed as Mean \pm SEM. Raw data for the mechanical hyperalgesia in Randall-Selitto test was calculated as the percentage change in maximum possible effect (\% MPE). The time-course curves were subjected to two-way (treatment $\times$ time) repeated measures analysis of variance (ANOVA) with Bonferroni's post hoc test. To determine the percentage inhibition for each treatment, the following formula was used:

$$
\% \text { inhibition }=\left(\frac{A U C_{\text {control }}-A U C_{\text {treatment }}}{A U C_{\text {control }}}\right) \times 100
$$

Differences in AUCs were analysed using one-way ANOVA with drug treatment as a between-subjects factor. Further comparisons between vehicle- and drug-treated groups were performed using the Newman-Keuls post hoc test. Doses for $50 \%$ of the maximal effect $\left(\mathrm{ED}_{50}\right)$ for each drug and $95 \%$ confidence intervals values were determined by using an iterative computer least squares method, with the following nonlinear regression (three-parameter logistic) using the formula:

$$
Y=\frac{a+(b-a)}{\left(1+10^{\left({\left.\log E D_{50}-X\right)}\right)}\right.}
$$

Where $X$ is the logarithm of dose and $Y$ is the response. $\mathrm{Y}$ starts at $a$ (the bottom) and goes to $b$ (the top) with a sigmoid shape.

The fitted mid-points $\left(\mathrm{ED}_{50} \mathrm{~s}\right)$ of the curves were compared statistically using $F$ test. GraphPad Prism for Windows version 5.01 (GraphPad Software, San Diego, CA, USA) was used for all statistical analyses and $\mathrm{ED}_{50}$ determinations. $P<0.05$ was taken to be statistically significant.

\section{RESULTS}

\section{Phytochemical screening}

Preliminary phytochemical screening of the extract revealed the presence of tannins, steroids, terpenoids, flavonoids, glycosides as well as oils and fats.

\section{Assessment of vincristine-induced cytotoxicity}

Vincristine-treated mice, unlike normal saline-treated mice, exhibited clear signs of toxicity evident as decrease in body weight and mortality (figure 1). There was an $11.11 \%$ reduction in mean body weight after vincristine treatment. One death was recorded on day six and two deaths were recorded on day ten and twelve each. None of the vincristine-injected mice showed any motor dysfunction or complication.

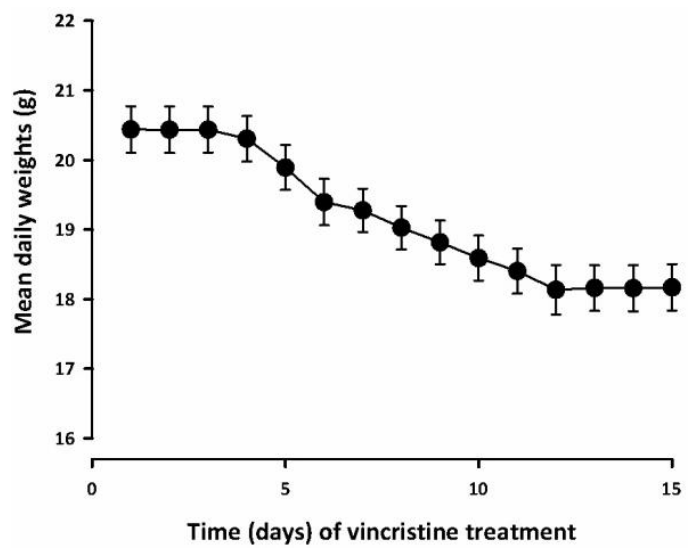

Fig. 1: Daily weights of mice $(\mathrm{n}=80)$ receiving vincristine $(0.1 \mathrm{mg} / \mathrm{kg} /$ day, i.p.).
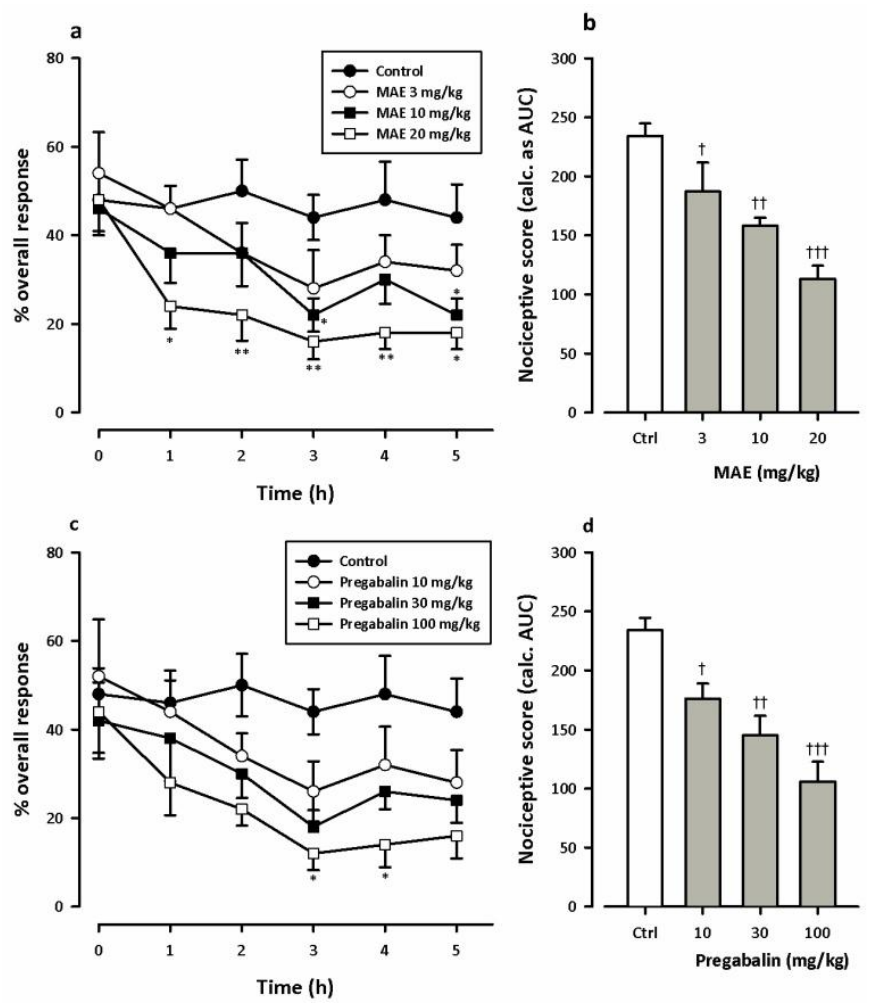

Fig. 2: Effect of (a) MAE (3-20 mg/kg, p.o.) and (c) pregabalin (10-100 mg/kg, p.o.) on the time course curves of vincristine-induced neuropathic pain (tactile allodynia, $4 \mathrm{~g}$ Von Frey filament) and the total nociceptive score (calculated as AUC) ( $b$ and d respectively) in mice. Data are expressed as mean \pm SEM $(\mathrm{n}=$ 5). ${ }^{*} P<0.05,{ }^{* *} P<0.01$ compared to control group (Two-way repeated measures ANOVA followed by Bonferroni's post hoc test). ${ }^{\dagger} \mathrm{P}<0.05,{ }^{\Uparrow \dagger} P<0.01$, ${ }^{\dagger \dagger \dagger} P<0.001$ compared to vehicle-treated (control) group (one-way ANOVA followed by Newman-Keuls post hoc test).

\section{Assessment of tactile allodynia using Von Frey filament of $4 \mathbf{g}$}

Administration of vincristine generated a distinct, protracted active tactile allodynia in mice. An hour after the different drug treatments, the normal saline-treated mice (control) exhibited increase response to tactile allodynia compared to the 
drug-treated mice. MAE (3-20 mg/kg, p.o.) dose-relatedly reduced the response to paw withdrawal $\left(F_{3,16}=11.56, P=0.0003\right.$, Figure 2a) producing tactile anti-allodynia of $51.7 \pm 11.3 \%$ at the highest dose used (Figure 2b). The anticonvulsant, pregabalin (10-100 $\mathrm{mg} / \mathrm{kg}$, p.o.) used as reference drug dose-dependently and significantly $\left(F_{3,16}=14.20, P<0.0001\right.$, Figure 2 c) blocked tactile allodynia with the highest dose $(100 \mathrm{mg} / \mathrm{kg})$ producing an antiallodynic effect of $54.7 \pm 16.6 \%$ (Figure $2 \mathrm{~d}$ ). The $\mathrm{ED}_{50}$ values showed MAE $(11.24 \pm 9.92 \mathrm{mg} / \mathrm{kg})$ was more potent than pregabalin $(17.23 \pm 9.63 \mathrm{mg} / \mathrm{kg})$.

\section{Assessment of intermediate hyperalgesia using Von Frey filament of $8 \mathrm{~g}$}

Von Frey filament of $8 \mathrm{~g}$ was used to measure the effect of MAE (3-20 mg/kg, p.o.) and pregabalin (10-100 mg/kg, p.o.) on intermediate hyperalgesia. MAE and pregabalin produced dosedependent and significant anti-hyperalgesia (MAE: $F_{3,16}=12.79$, $P=0.0002$ and pregabalin: $F_{3,16}=28.99, P<0.0001$, Figure $3 \mathrm{a}$ and $\mathrm{c}$ ).
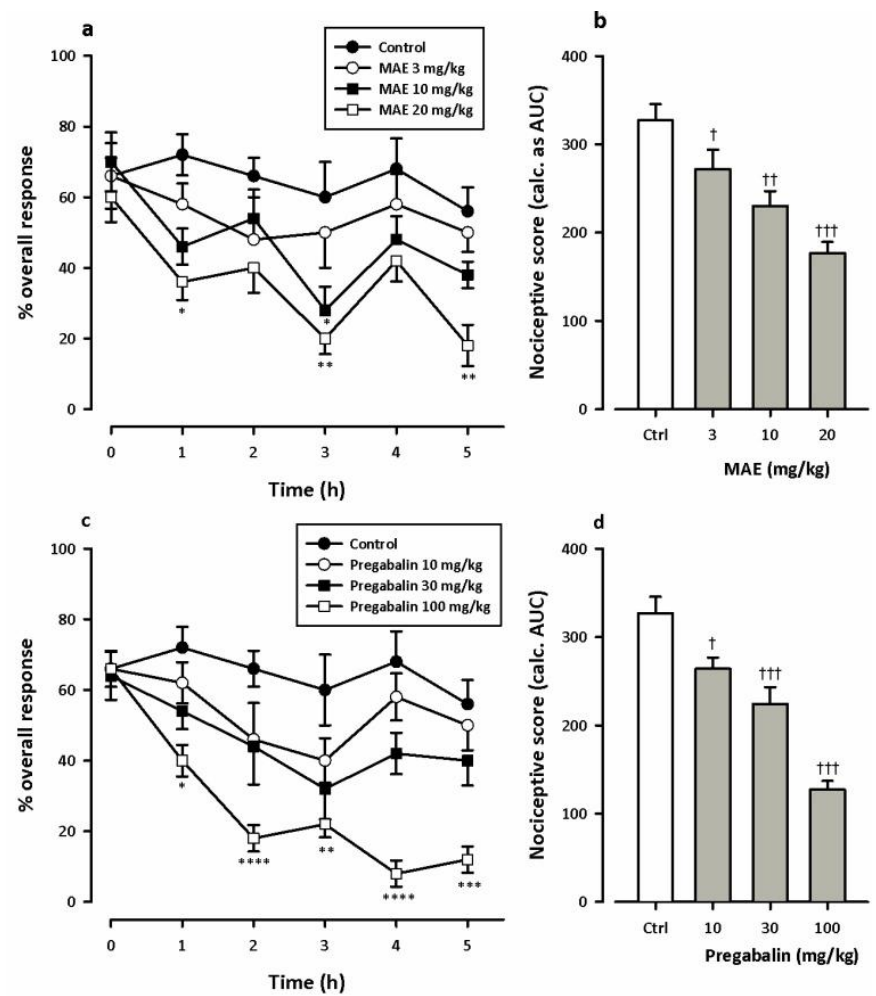

Fig. 3: Effect of MAE $(3-20 \mathrm{mg} / \mathrm{kg}$, p.o. $)(\mathrm{a})$, and pregabalin $(10-100$ $\mathrm{mg} / \mathrm{kg}$, p.o.) (c), on the time course curves of vincristine-induced neuropathic pain ( $8 \mathrm{~g}$ Von Frey filament) and the total nociceptive score (calculated as AUC) ( $b$ and d respectively) in mice. Data are expressed as mean \pm SEM $(\mathrm{n}=$ 5). ${ }^{*} P<0.05,{ }^{* * *} P<0.01,{ }^{* * * *} P<0.001,{ }^{* * * * *} P<0.0001$ compared to vehicle-treated (control) group (Two-way repeated measures ANOVA followed by Bonferroni's post hoc test). ${ }^{\dagger} \mathrm{P}<0.05,{ }^{\dagger \dagger} \mathrm{P}<0.01,{ }^{\dagger \dagger} \mathrm{P}<0.001$ compared to vehicletreated (control) group (One-way ANOVA followed by Newman-Keuls post hoc test).

The highest doses of MAE and pregabalin produced maximum anti-hyperalgesic effects of $45.8 \pm 12.3$ and $61.2 \pm 9.8$ $\%$ respectively (Figure $3 \mathrm{~b}$ and $\mathrm{d}$ ). The $\mathrm{ED}_{50}$ values showed MAE
$(12.04 \pm 9.39 \mathrm{mg} / \mathrm{kg})$ was more potent than pregabalin $(47.79 \pm$ $19.58 \mathrm{mg} / \mathrm{kg})$.

\section{Assessment of mechanical hyperalgesia using Von Frey filament of $15 \mathrm{~g}$}

Administration of vincristine intraperitoneally in two cycles of five consecutive days with two days off between the cycles generated a marked, static mechanical hyperalgesia in both hind paws of the mice on day 15 .

The normal saline-treated mice (control) exhibited increase response to mechanical hyperalgesia compared to the drug-treated mice. Von Frey filament of $15 \mathrm{~g}$ was used to measure the effect of MAE (3-20 mg/kg p.o.) and pregabalin (10-100 $\mathrm{mg} / \mathrm{kg}$ p.o.) on mechanical hyperalgesia. MAE and pregabalin produced dose-dependent and significant anti-hyperalgesia (MAE: $F_{3,16}=14.30, P<0.0001$ and pregabalin: $F_{3,16}=13.04, P=0.0001$, Figure $4 \mathrm{a}$ and $\mathrm{c}$ ).

The highest doses of MAE and pregabalin produced maximum anti-hyperalgesic effects of $43.9 \pm 15.7$ and $45.1 \pm 15.4$ $\%$ respectively (Figure $4 \mathrm{~b}$ and $\mathrm{d}$ ). The $\mathrm{ED}_{50}$ values showed MAE $(13.78 \pm 8.61 \mathrm{mg} / \mathrm{kg})$ was more potent than pregabalin $(31.66 \pm$ $15.38 \mathrm{mg} / \mathrm{kg})$.
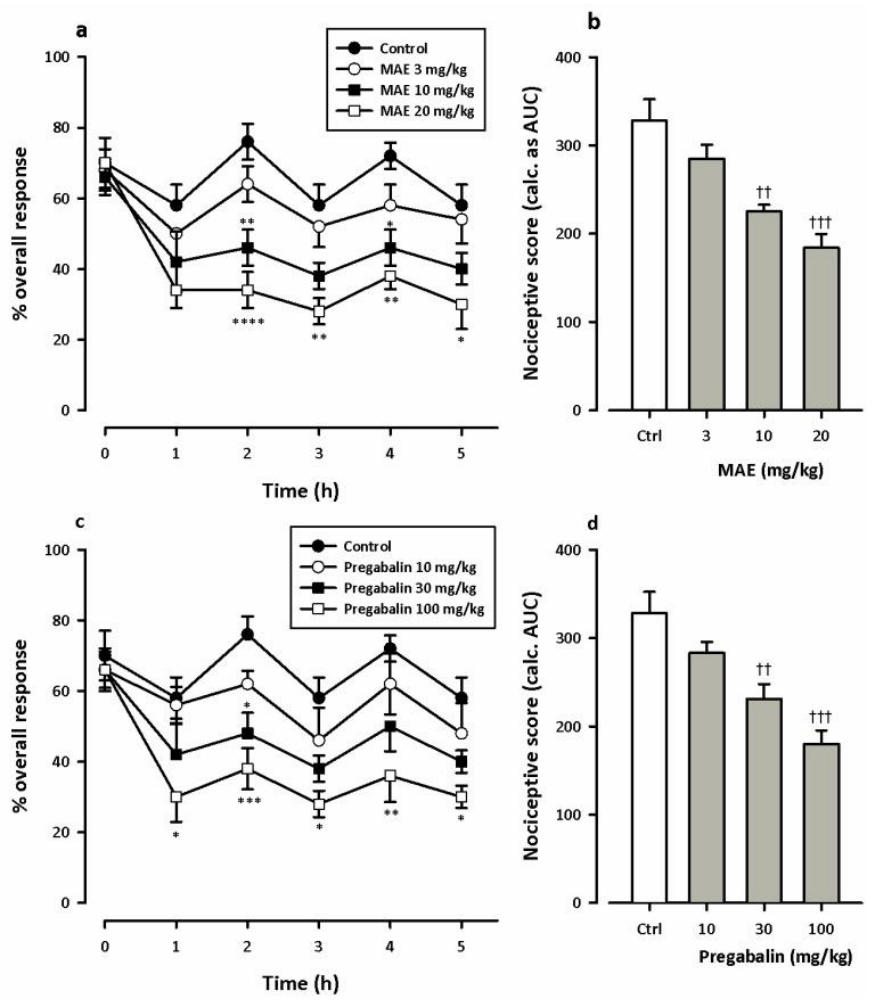

Fig. 4: Effect of MAE (3 - $20 \mathrm{mg} / \mathrm{kg}$, p.o.) (a), and pregabalin (10 - 100 $\mathrm{mg} / \mathrm{kg}$, p.o.) (c), on the time course curve of vincristine-induced neuropathic pain (15 g Von Frey filament) and the total nociceptive score (calculated as AUC) (b and d respectively) in mice. Data are expressed as mean \pm SEM ( $\mathrm{n}=$ 5). ${ }^{*} P<0.05,{ }^{* *} P<0.01,{ }^{* * *} P<0.001,{ }^{* * * *} P<0.0001$ compared to vehicle-treated (control) group (Two-way repeated measures ANOVA followed by Bonferroni's post hoc test). ${ }^{\dagger \dagger} \mathrm{P}<0.01,{ }^{\dagger \dagger} \mathrm{P}<0.001$ compared to vehicle-treated (control) group (One-way ANOVA followed by Newman-Keuls post hoc test) 


\section{Assessment of mechanical hyperalgesia in the Randall-Selitto} test

In the Randall-Selitto test, baseline mechanical hyperalgesia measured on day 15 showed that both hind paws demonstrated distinct mechanical hyperalgesia. A change in hyperalgesia was calculated as \% MPE. MAE (3-20 mg/kg, p.o.) and pregabalin (10-100 mg/kg, p.o.) generated dose-dependent and significant inhibition of mechanical hyperalgesia (MAE: $F_{3,16}=$ 9.162, $P=0.0009$; pregabalin: $F_{3,16}=20.89, P<0.0001$; Figure 5a and $\mathrm{c})$. The highest doses of MAE and pregabalin produced maximum anti-hyperalgesic effects of $72 \pm 10.8$ and $52.8 \pm 14.5 \%$ respectively (Figure $5 \mathrm{~b}$ and $\mathrm{d}$ ). The $\mathrm{ED}_{50}$ values obtained demonstrated that MAE $(10.08 \pm 8.50 \mathrm{mg} / \mathrm{kg})$ was more potent than pregabalin $(43.65 \pm 23.18 \mathrm{mg} / \mathrm{kg})$.
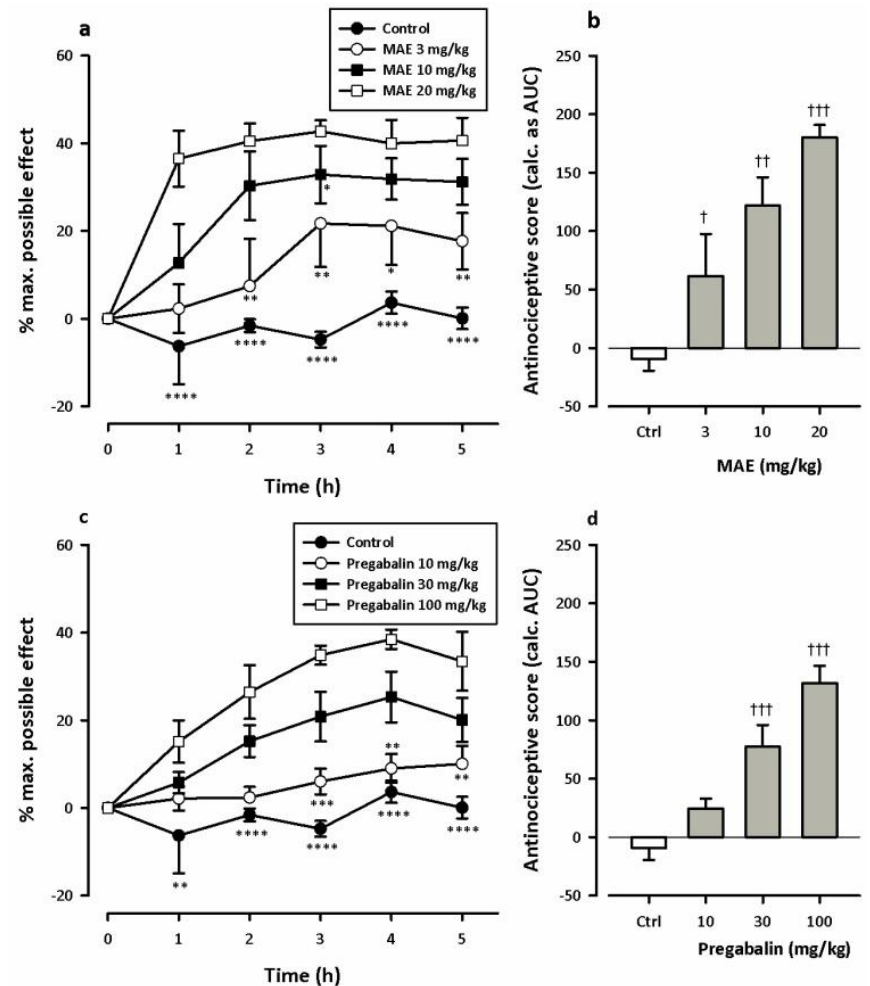

Fig. 5: Effect of MAE $(3-20 \mathrm{mg} / \mathrm{kg}$, p.o. $)(\mathrm{a})$, and pregabalin $(10-100$ $\mathrm{mg} / \mathrm{kg}$, p.o.) (c), on the time course curve of vincristine-induced neuropathic pain (Randall-Selitto) and the total anti-nociceptive score (calculated as AUC) (b and d respectively) in mice. Data are expressed as mean \pm SEM $(\mathrm{n}=5)$. ${ }^{*} P<0.05,{ }^{* *} P<0.01,{ }^{* * *} P<0.001,{ }^{* * * *} P<0.0001$ compared to vehicle-treated (control) group (Two-way repeated measures ANOVA followed by Bonferroni's post hoc test). ${ }^{\dagger} \mathrm{P}<0.05,{ }^{\dagger \dagger} \mathrm{P}<0.01,{ }^{\dagger \dagger} \mathrm{P}<0.001$ compared to vehicletreated (control) group (One-way ANOVA followed by Newman-Keuls post hoc test)

\section{Assessment of cold allodynia in cold water at $4.5^{\circ} \mathrm{C}$}

Baseline cold allodynia was determined from both hind paws on day 15 in cold water set at a temperature of $4.5^{\circ} \mathrm{C}$. MAE (3-20 mg/kg, p.o.) and pregabalin $(10-100 \mathrm{mg} / \mathrm{kg}$, p.o.) produced significant (MAE: $F_{4,20}=42.58, P<0.0001$; pregabalin: $F_{4,20}=$ 44.89, $P<0.0001)$ and dose-dependent inhibition of cold allodynia (Figure 6a and c) exhibited as increased latency to paw withdrawal. The highest doses of MAE and pregabalin used increased the time to paw withdrawal to cold allodynia by $125.5 \pm$ 3.07 and $116.7 \pm 2.68 \%$ respectively (Figure $6 \mathrm{~b}$ and $\mathrm{d}$ ). The $\mathrm{ED}_{50}$ values obtained revealed that MAE $(3.80 \pm 1.69 \mathrm{mg} / \mathrm{kg})$ was more potent than pregabalin $(42.74 \pm 20.36 \mathrm{mg} / \mathrm{kg})$.
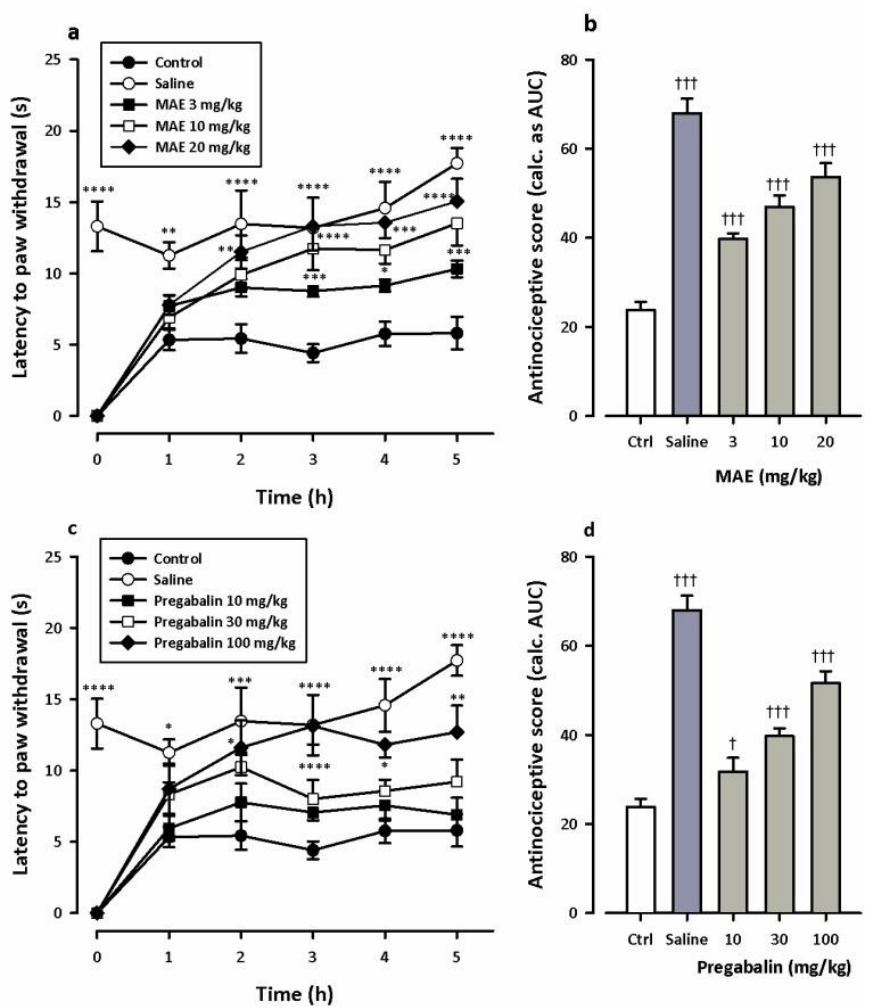

Fig. 6: Effect of MAE (3 - $20 \mathrm{mg} / \mathrm{kg}$, p.o.) (a), and pregabalin $(10-100$ $\mathrm{mg} / \mathrm{kg}$, p.o.) (c), on the time course curve of vincristine-induced cold allodynia (cold water at $4.5^{\circ} \mathrm{C}$ ) and the total anti-nociceptive score (calculated as AUC) (b and d respectively) in mice. Data are expressed as mean \pm SEM $(\mathrm{n}=5)$. ${ }^{*} P<0.05,{ }^{* *} P<0.01,{ }^{* * *} P<0.001,{ }^{* * * * *} P<0.0001$ compared to vehicle-treated (control) group (Two-way repeated measures ANOVA followed by Bonferroni's post hoc test). ${ }^{\dagger} \mathrm{P}<0.05,{ }^{\dagger \dagger} \mathrm{P}<0.01,{ }^{\dagger \dagger} \mathrm{P}<0.001$ compared to vehicletreated (control) group (One-way ANOVA followed by Newman-Keuls post hoc test)

\section{DISCUSSION}

This study shows that orally administered petroleum ether/ethyl acetate stem bark extract of Maerua angolensis dosedependently improved vincristine-induced mechanical hyperalgesia as well as tactile and cold allodynia. Vincristine, paclitaxel and other chemotherapeutic agents have been reported to produce peripheral neurotoxicity, with patients reporting sensory abnormalities and neuropathic pain during and often persisting after therapy (Lynch et al., 2005; Muthuraman et al., 2011). This is a dose-limiting side effect lacking validated drugs for its prevention and control. Different chemotherapeutic agents have separate mechanism(s) of induction, thus, the therapy would as well require being specific for each chemotherapeutic agent (Kaley et al., 2009). Considering the aforementioned, the antinociceptive effect of MAE can be said to be significant in the vincristine-induced neuropathic pain model. Furthermore, administration of the extract after the occurrence of neuropathic 
pain (post-treatment) suggested its curative effect for chemotherapy-induced neuropathic pain. Vincristine is thought to produce peripheral neuropathy by increased oxidative stress parameters such as lipid peroxidation and superoxide anions (Kaur et al., 2010; Muthuraman et al., 2011). The extract then could through its anti-oxidant effects (Meda et al., 2013) influenced the anti-nociception on vincristine-induced neuropathic pain. Vincristine therapy for human adenocarcinoma cells triggers nuclear factor- $\kappa \mathrm{B}(\mathrm{NF}-\kappa \mathrm{B})$ in a dose-dependent way (Park et al., 2012). In addition, systemic therapy with vincristine injures Schwann cells and dorsal root ganglion (DRG) neurons of the PNS resulting in degeneration of myelinated and unmyelinated fibres (Jaggi et al., 2012). It has also been reported that vincristine therapy inhibits the axonal transport of the sciatic nerve in rats (Park et al., 2012), thus the direct effect on peripheral nerves probably is a further mechanism of vincristine-induced neuropathic pain. Both central and peripheral mechanisms are implicated in vincristine-induced peripheral neuropathy. The small diameter $\mathrm{C}$ - and A $\delta$-sensory fibres (high threshold fibres) are mostly engaged in the response to cold and strong mechanical stimuli but large A $\beta$-sensory fibres (low threshold fibres) response to tactile stimuli. Peripherally, the interleukin-6-janus kinasetranscription-3 pathway; and centrally, TNF- $\alpha$ - p38 mitogenactivated protein kinase (MAPK) pathway have been implicated (Aley et al., 2002; Siau et al., 2006; Kiguchi et al., 2008) The extract therefore may have exerted analgesic effect in this study by blocking the phosphorylation of extracellular signal-related kinases and p38 MAPK action, and also by decreasing NF- $\kappa$ B. Furthermore, the extract probably curbed the generation of nitric oxide (NO), interleukins and TNF- $\alpha$. Increase in TNF- $\alpha$ has been reported in the sciatic nerve of rats with vincristine-induced neuropathic pain (Kiguchi et al., 2008; Muthuraman et al., 2011). The NO second-messenger paths have been shown to play a role in hyperalgesia in the vincristine-induced neuropathic pain model in rats (Yajima et al., 2005). Additionally, inhibitors of NO synthase demonstrating anti-hyperalgesia in vincristine-induced neuropathic pain imply that NO synthase pathways are linked with vincristineinduced hyperalgesia (Bujalska et al., 2009). Consequently, the stem bark of Maerua angolensis possibly inhibit NO, TNF- $\alpha$ and $\mathrm{NF}-\kappa \mathrm{B}$ in this study through its anti-inflammatory effects (Adamu et al., 2007). The functional improvement or the inhibition of decrease of the Schwann cells, myelinated axons, nerve conduction velocity and axonal transport (neuroprotective effects) could perhaps be another mechanism by which MAE exert its action in this study.

Enhanced expression and action of $\alpha_{2}-\delta_{1} \mathrm{Ca}^{2+}$ channels, a subunit form of $\mathrm{N}$-type voltage-dependent $\mathrm{Ca}^{2+}$ channel is also reported in neuropathic pain conditions (Yajima et al., 2005; Zamponi et al., 2009). Inhibition of calcium channels stop neuronal excitability and other cellular enzymatic cascade reactions that guide to pain sensations and pain stimuli transmission in the affected myelinated and unmyelinated C-, A $\delta$ - and A $\beta$-fibres (Schim, 2009; Zamponi et al., 2009; Kumar et al., 2010). Pregabalin, an antagonist of $\alpha_{2}-\delta_{1}$ subunit of voltage-dependent calcium channels is known to be useful both clinically and experimentally in neuropathic pain (Bujalska et al., 2009; Schim, 2009). The extract then could have also produced analgesic effect in this study by blocking calcium channels on sensory nerves similar to pregabalin. The exact mechanism(s) of action of MAE, however, remains to be established.

\section{CONCLUSION}

In summary, orally administered MAE dose-dependently inhibited tactile and cold allodynia in addition to mechanical hyperalgesia induced by vincristine in mice. This suggests that MAE may exert analgesic effect in cancer patients with vincristine-induced neuropathic pain.

\section{ACKNOWLEDGEMENT}

The authors are grateful for the technical assistance offered by Messrs Thomas Ansah, Gordon Darku and Prosper Akortia of the Department of Pharmacology, Faculty of Pharmacy and Pharmaceutical Sciences, KNUST, Kumasi

\section{CONFLICT OF INTEREST STATEMENT}

The authors declare that there is no conflict of interest regarding the publication of this paper.

\section{RERERENCES}

Adamu A, Abdurahman E, Ibrahim H, Abubakar M, Magaji M, Yaro A. Effect of Aqueous methanolic stem-bark extract of Maerua angolensis DC on acute and sub-acute inflammations. Nig J Pharm Sci, 2007; 6:1-7.

Alessandri-Haber N, Dina OA, Yeh JJ, Parada CA, Reichling DB, Levine JD. Transient receptor potential vanilloid 4 is essential in chemotherapy-induced neuropathic pain in the rat. J Neurosci, 2004; 24:4444-4452.

Aley KO, Levine JD. Different peripheral mechanisms mediate enhanced nociception in metabolic/toxic and traumatic painful peripheral neuropathies in the rat. Neuroscience, 2002; 111:389-397.

Bujalska M, Makulska-Nowak H. Bradykinin receptors antagonists and nitric oxide synthase inhibitors in vincristine and streptozotocin induced hyperalgesia in chemotherapy and diabetic neuropathy rat model. Neuro Endocrinol Lett, 2009; 30:144-152.

Ebadi M. 2007. Pharmacodynamic basis of herbal medicine. Boca Raton: CRC Press, Taylor \& Francis Group.

Flatters SJ, Bennett GJ. Ethosuximide reverses paclitaxel- and vincristine-induced painful peripheral neuropathy. Pain, 2004; 109:150161.

Iliya H, Boakye-Gyasi E, Adongo W, Ampadu F, Woode E. Antinociceptive activity of various solvent extracts of Maerua angolensis DC stem bark in rodents. Phytopharmacology, 2014a; 13:1-8.

Iliya HA, Woode E. Evaluation of Analgesic Property of Petroleum Ether/Ethyl Acetate Stem Bark Extract and Fractions of Maerua angolensis in Murine Models of Pain. J App Pharm Sci, 2014b; 5:091-102.

Jaggi AS, Singh N. Mechanisms in cancer-chemotherapeutic drugs-induced peripheral neuropathy. Toxicology, 2012; 291:1-9.

Kaley TJ, Deangelis LM. Therapy of chemotherapy-induced peripheral neuropathy. Br J Haematol, 2009; 145:3-14.

Kaur G, Jaggi AS, Singh N. Exploring the potential effect of Ocimum sanctum in vincristine-induced neuropathic pain in rats. J Brachial Plex Peripher Nerve Inj, 2010; 5:3. 
Kiguchi N, Maeda T, Kobayashi Y, Kishioka S. Up-regulation of tumor necrosis factor-alpha in spinal cord contributes to vincristineinduced mechanical allodynia in mice. Neurosci Lett, 2008; 445:140-143.

Kumar N, Laferriere A, Yu JS, Poon T, Coderre TJ. Metabotropic glutamate receptors (mGluRs) regulate noxious stimulusinduced glutamate release in the spinal cord dorsal horn of rats with neuropathic and inflammatory pain. J Neurochem, 2010; 114:281-290.

Lynch JJ, 3rd, Wade CL, Mikusa JP, Decker MW, Honore P. ABT-594 (a nicotinic acetylcholine agonist): anti-allodynia in a rat chemotherapy-induced pain model. Eur J Pharmacol, 2005; 509:43-48.

Meda N, Bangou M, Bakasso S, Millogo-Rasolodimby J, Nacoulma O. Antioxidant activity of phenolic and flavonoid fractions of Cleome gynandra and Maerua angolensis of Burkina Faso. J App Pharm Sci, 2013; 3:036-042.

Mothana RA, Lindequist U, Gruenert R, Bednarski PJ. Studies of the in vitro anticancer, antimicrobial and antioxidant potentials of selected Yemeni medicinal plants from the island Soqotra. BMC Complement Altern Med, 2009; 9:7.

Muthuraman A, Singh N, Jaggi AS. Protective effect of Acorus calamus L. in rat model of vincristine induced painful neuropathy: an evidence of anti-inflammatory and anti-oxidative activity. Food Chem Toxicol, 2011; 49:2557-2563.

Park HJ, Lee HG, Kim YS, Lee JY, Jeon JP, Park C, Moon DE. Ginkgo biloba extract attenuates hyperalgesia in a rat model of vincristineinduced peripheral neuropathy. Anesth Analg, 2012; 115:1228-1233.

Quintans JS, Antoniolli AR, Almeida JR, Santana-Filho VJ, Quintans-Junior LJ. Natural products evaluated in neuropathic pain models - a systematic review. Basic Clin Pharmacol Toxicol, 2014; 114: $442-450$.

Schim JD. Neuropathic pain: Diagnosis and new treatment options. 22nd US Psychiatric and Mental Health Congress, 2009.

Siau C, Xiao W, Bennett GJ. Paclitaxel- and vincristine-evoked painful peripheral neuropathies: loss of epidermal innervations and activation of Langerhans cells. Exp Neurol, 2006; 201:507-514.
Trease GE, Evans WC. 1989. A Textbook of Pharmacognosy. 13th ed. London: Baillière Tindall.

Vissers KC, Geenen F, Biermans R, Meert TF. Pharmacological correlation between the formalin test and the neuropathic pain behavior in different species with chronic constriction injury. Pharmacol Biochem Behav, 2006; 84:479-486.

Wolf S, Barton D, Kottschade L, Grothey A, Loprinzi C. Chemotherapy-induced peripheral neuropathy: prevention and treatment strategies. Eur J Cancer, 2008; 44:1507-1515.

Woode E, Ameyaw EO, Ainooson GK, Abotsi WK, BoakyeGyasi E, Kyekyeku JO. Analgesic Effects of an Ethanol Extract of the Fruits of Xylopia aethiopica and Xylopic Acid in Murine Models of Pain: Possible Mechanism(s). Pharmacologia, 2013; 4:285-300.

Yajima Y, Narita M, Usui A, Kaneko C, Miyatake M, Narita M, Yamaguchi T, Tamaki H, Wachi H, Seyama Y, Suzuki T. Direct evidence for the involvement of brain-derived neurotrophic factor in the development of a neuropathic pain-like state in mice. J Neurochem, 2005; 93:584-594.

Zamponi GW, Lewis RJ, Todorovic SM, Arneric SP, Snutch TP. Role of voltage-gated calcium channels in ascending pain pathways. Brain Res Rev, 2009; 60:84-89.

Zhang ZJ. Therapeutic effects of herbal extracts and constituents in animal models of psychiatric disorders. Life Sci, 2004; 75:1659-1699.

\section{How to cite this article:}

Hosea Azi Iliya, Wonder Kofi Mensah Abotsi, Charles Benneh, Eric Woode., Maerua angolensis Extract Reduces Allodynia and Hyperalgesia in a Mouse Model of Vincristine-Induced Peripheral Neuropathy. J App Pharm Sci, 2016; 6 (05): 124-130. 